\title{
Direct synthesis of ZSM-5 from kaolin and the influence of organic template
}

\author{
Rustam ${ }^{a, b}$, Ratna Ediati ${ }^{b}$, Berty Septiyana ${ }^{b}$, Yusuf Muhammad Zein ${ }^{b}$, Hasliza Bahruji c , Imroatul \\ Qoniah ${ }^{\mathrm{d}}$, Hartati e, Hadi Nur ${ }^{\mathrm{f}}$, Didik Prasetyoko ${ }^{\mathrm{b}, *}$ \\ ${ }^{a}$ Department of Chemistry, Faculty of Education, Kandahar University (KU), Kandahar, Afghanistan \\ ${ }^{b}$ Department of Chemistry, Faculty of Mathematics and Natural Sciences, Institut Teknologi Sepuluh Nopember (ITS), Surabaya, Indonesia \\ ${ }^{c}$ Cardiff Catalysis Institute, Cardiff University, CF10 3AT Cardiff United Kingdom \\ ${ }^{a}$ Department of Environmental Engineering, Faculty of Civil and Planning Engineering, Islamic University of Indonesia, Yogyakarta, Indonesia \\ e Department of Chemistry, Faculty of Science and Technology, Universitas Airlangga, Surabaya, 60115, Indonesia \\ ${ }^{f}$ Centre for Sustainable Nanomaterials, Ibnu Sina Institute for Scientific Studies and Industrial Research, Universiti Teknologi Malaysia (UTM), \\ Skudai 81310, Johor, Malaysia
}

* Corresponding author: didikp@chem.its.ac.id

\section{Article history \\ Received 21 March 2017 \\ Accepted 3 May 2017}

\section{Graphical abstract}

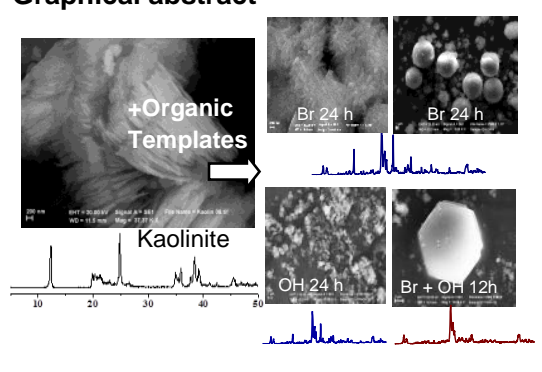

\section{Abstract}

We investigated the transformation of kaolin to ZSM- 5 using hydrothermal synthesis method and the influence of organic template as a structure-directing agent. The formation of ZSM-5 from kaolin occurred via dissolution of kaolin to form amorphous silica. Zeolite-like analcime produced when the hydrothermal treatment was extended to $18 \mathrm{~h}$. We found synergistic effect of using a mixture of TPAOH and TPABr organic template to enhance kaolin dissolution, initiate ZSM-5 formation and inhibit the transformation of ZSM- 5 to analcime. The ZSM- 5 framework formed after crystallization for $6 \mathrm{~h}$ by using the mixture of TPAOH and TPABr, while when using TPAOH or TPABr only, ZSM- 5 formed at longer crystallization time, i.e. $12 \mathrm{~h}$.

Keywords: Crystallization time, kaolin, phase transformation, TPABr, TPAOH, ZSM-5

\section{INTRODUCTION}

ZSM-5 has been widely used as catalyst in petrochemical process because of the high surface area that allows the adsorption of reactant molecules (Kim and Chung, 2003). The ZSM-5 is a robust material with high thermal and acid stability; its unique pore channel system makes a good catalyst to achieve high conversion and selectivity of desired product (Wang et al., 2007). The synthesis of ZSM-5 from natural mineral sources and waste materials has been reported mainly to reduce the cost of production and to utilize the waste minerals. Serpentine (Kim and Chung, 2003), rice husk ash (Prasetyoko et al., 2012), fly ash (Tanaka and Fujii, 2009), expanded perlite (Wang et al., 2007) and kaolinite (Feng et al., 2009; Pan et al., 2014) were previously reported as precursor in ZSM-5 zeolite synthesis. These minerals are generally rich with $\mathrm{SiO}_{2}$ and $\mathrm{Al}_{2} \mathrm{O}_{3}$ which make them perfect candidates for zeolite synthesis. The use of metakaolin, a reactive phase of calcined kaolin, as raw materials for the synthesis of ZSM-5 has been reported which requires the heat treatment of kaolin up to $600-1100{ }^{\circ} \mathrm{C}$ (Feng et al., 2009; Alkan et al., 2005). According to Johnson and Arshad (2014), this activation process promotes kaolin to metastable phase and becomes highly reactive for zeolites formation.

Hydrothermal synthesis of zeolite is influenced by temperature and crystallization time, which these parameters can affect the process of zeolite formation, the $\mathrm{Si}$ and $\mathrm{Al}$ content in the framework and also the stability of the zeolite (Shiralkar and Clearfield, 1989). In order to orientate the crystal growth, the synthesis was usually performed in the presence of organic template as a structure-directing agent, typically tetrapropylammonium cations. This cation is trapped in the zeolite pores during crystal growth and removed by calcination in air at high temperature (Pan et al., 2014). The role of this organic structure-directing agent mimics the kinetics of complex nucleation and crystallization processes (Byrappa and Yoshimura, 2013). Alkalinity also has a vital role in the crystal growth of zeolite as the $\mathrm{OH}$ anions acts as mineralizing agent. Increasing the $\mathrm{pH}$ of the mixture improves the dissolution of $\mathrm{Si}$ and $\mathrm{Al}$ oxides or hydroxides precursor to become a homogeneous solution (Karimi et al., 2012). The increasing of $\mathrm{OH}^{-}$concentration accelerates the crystals growth and shortens the period of induction time for the nucleation to occur.

The potential of kaolin as mineral source ( $\mathrm{Si}$ and $\mathrm{Al}$ ) for ZSM-5 synthesis was investigated in this study. Kaolin was used without prior pretreatment in the presence of TPAOH and/or TPABr as a structure-directing agent. Metakaolinite was generally used for mineral source of ZSM-5 synthesis. Another publication has examine that kaolin can be directly used as mesoporous aluminosilicates (Qoniah et al., 2015). Hydrothermal synthesis was carried out for 6, 12,18 , and $24 \mathrm{~h}$ in order to investigate the mechanism of kaolin transformation to ZSM-5. Detail analysis of the solid products using XRD, FTIR and SEM analysis gives information on the purity, crystallinity, morphology and thermal stability of resulting ZSM-5.

\section{EXPERIMENTAL}

\section{Materials}


Materials in this study were used without pretreatment. Kaolin was obtained from Bangka Belitung Island, Indonesia (XRF results: $\mathrm{SiO}_{2} 57 \mathrm{wt} \%, \mathrm{Al}_{2} \mathrm{O}_{3} 22 \mathrm{wt} \%, \mathrm{P}_{2} \mathrm{O}_{5} 3.9 \mathrm{wt} \%, \mathrm{~K}_{2} \mathrm{O} 3.22 \mathrm{wt} \%, \mathrm{CaO} 1.8$ wt $\%, \mathrm{TiO}_{2} 2.2 \mathrm{wt} \%, \mathrm{~V}_{2} \mathrm{O}_{5} 0.15 \mathrm{wt} \%, \mathrm{Fe}_{2} \mathrm{O}_{3} 8.89$ wt $\%$, other compounds $0.84 \mathrm{wt} \%)$ sodium hydroxide pellets $(\mathrm{NaOH}, \geq 99 \mathrm{wt} \%$, Merck), tetrapropylammonium bromide (TPABr, $\geq 99 \mathrm{wt} \%$, Merck), tetrapropylammonium hydroxide (TPAOH, 40 wt.\%, Merck), colloidal silica (Ludoxn HS-30, $30 \mathrm{wt} \%$ ), and distilled water.

\section{Synthesis of ZSM-5}

ZSM-5 was prepared by hydrothermal synthesis method with a molar composition of reactant is in the ratio of $10 \mathrm{Na}_{2} \mathrm{O}: 100 \mathrm{SiO}_{2}: 2$ $\mathrm{Al}_{2} \mathrm{O}_{3}: 1800 \mathrm{H}_{2} \mathrm{O}: 0-20$ TPA (TPABr / TPAOH) (Prasetyoko et al., 2012). Kaolin and $\mathrm{NaOH}$ was mixed with distilled water under a vigorous stirring followed by gradual addition of ludox to the mixture. The mixture was vigorously stirred for another $2 \mathrm{~h}$. The organic template was added to the mixture and stirred for $6 \mathrm{~h}$ at room temperature at $400 \mathrm{rpm}$. Resulting gel was aged for $12 \mathrm{~h}$ at room temperature before transferred into an autoclave for hydrothermal crystallization at $175^{\circ} \mathrm{C}$ for $6,12,18$, and $24 \mathrm{~h}$. After completion of the reaction, the synthesized product was cooled immediately to room temperature to stop the crystallization process. The obtained solid product was filtered and rinsed with copious amount of distilled water. Finally, the solids were dried at $120^{\circ} \mathrm{C}$ for $12 \mathrm{~h}$. Samples were denoted based on its crystallization time and the type of organic template. For example Br-6 h is used for sample obtained at $6 \mathrm{~h}$ using TPABr.

\section{Characterization of the Obtained Solid}

The solid samples were characterized using X-ray diffraction technique (XRD JOEL JDX-3530 X-ray Diffractometer) with $\mathrm{Cu} \mathrm{K \alpha}$ radiation of wavelength $1.5418 \AA(40 \mathrm{kV}$ and $30 \mathrm{~mA})$ over the scanning range $2 \theta=5-50^{\circ}$. Different functional groups of the samples were identified by FT-IR spectroscopy analysis (Shimadzu Spectrum One 8400S Spectrophotometer) in the range between $400-1400 \mathrm{~cm}^{-1}$ using $\mathrm{KBr}$ pellets technique. Scanning electron microscope (SEM) image was monitored using a ZEISS EVO MA 10 to monitor morphology and particle size. Electron dispersed X-ray (EDX) (BRUKER $129 \mathrm{EV}$ ) was used to determine the chemical composition of the samples.

\section{RESULTS AND DISCUSSION}

\section{X-ray Diffraction (XRD)}

The XRD patterns of the samples obtained from the reaction mixture at various synthetic conditions are presented in Fig 1. Fig 1A illustrates the XRD pattern of synthesis powder without the presence of organic template. The peaks at $2 \theta=12.3,24.8,38.3^{\circ}$ in Fig. 1 A (a) are corresponded to the crystalline structure of kaolin (Feng et al., 2009). Kaolin is dissolved in $\mathrm{NaOH}$ solution to form presumably amorphous silica. The dissolution however is not complete even after $6 \mathrm{~h}$ of hydrothermal treatment. The XRD pattern of samples for $12 \mathrm{~h}$, $18 \mathrm{~h}$, and $24 \mathrm{~h}$ showed a broad peak centered at $\sim 2 \theta=25^{\circ}$ with no diffraction peaks from any kind of crystal. This characteristic is corresponded to the amorphous silica structure.

Fig. 1B-D shows the XRD patterns of solid product obtained from the reaction using organic template as a structure-directing agent. Similar XRD pattern were found on solid products for the reaction mixture without organic template after $6 \mathrm{~h}$ of reaction. The peaks observed at $2 \theta=7.97,8.87,23.1,24.4^{\circ}$ were identified as ZSM-5 structure as reported by Treacy and Higgins, (2001). These characteristics peak appeared for all reaction mixtures regardless the organic template used in the systems. Detail analysis of the XRD data were shown in Table 1.

Although the ZSM-5 was successfully formed at $12 \mathrm{~h}$ of crystallization, prolonged time of hydrothermal treatment is necessary to increase the crystallinity of the structure. Small peaks appeared at $2 \theta=15.9,26.1,30.7^{\circ}$ were observed that corresponded to the characteristic peaks of analcime structure (Park et al., 2012). TPABr template gives high stability of ZSM- 5 evidence by the transformation to analcime only occurs after $18 \mathrm{~h}$ of reaction. In the presence of both $\mathrm{TPAOH}$ and TPABr, the analcime phase also formed after $18 \mathrm{~h}$ of reaction. In contrast TPAOH containing reaction mixtures formed analcime after $12 \mathrm{~h}$ of reaction. This occured when the higher of $\mathrm{NaOH}$ concentration produced the mixture of zeolite like analcime (Johnson and Arshad, 2014).

\section{FTIR Spectroscopy}

The fresh kaolin sample and resulting ZSM-5 were analyzed using infrared spectroscopy. The infrared spectra of the kaolin showed the characteristic peak at $1115,1030,1007 \mathrm{~cm}^{-1}$ which are assigned to the $\mathrm{TO}_{4}(\mathrm{~T}=\mathrm{Si}$ or $\mathrm{Al})$ asymmetric stretching vibrations (Fig. 2) (Rios et al., 2009). The adsorption peaks at $798 \mathrm{~cm}^{-1}$ and $1096 \mathrm{~cm}^{-1}$ are belong to the stretching vibration of typical of $\mathrm{Si}^{-} \mathrm{O}-\mathrm{Si}$ bond, whilst the peak at around $460 \mathrm{~cm}^{-1}$ is assigned to $\mathrm{TO}_{4}$ bending vibration. Strong inner $\mathrm{OH}$ bending peak was observed at around $912 \mathrm{~cm}^{-1}$, symmetric stretching of $\mathrm{AlO}_{4}$ at around $800,792,689 \mathrm{~cm}^{-1}$, double ring or Al-O octahedral stretching at $550 \mathrm{~cm}^{-1}$ and $\mathrm{T}-\mathrm{O}(\mathrm{T}=\mathrm{Si}$ or $\mathrm{Al})$ bending at $450 \mathrm{~cm}^{-1}$. The stretching vibration of $\mathrm{Al}(\mathrm{O}, \mathrm{OH})_{6}$ octahedral in the kaolin is observed at $536 \mathrm{~cm}^{-1}$ region (Feng et al., 2009).

Table 1 Total crystallinity of the obtained samples in the presence of TPABr, TPAOH, and TPABr + TPAOH

\begin{tabular}{|c|c|c|c|c|c|c|c|c|c|c|c|c|c|c|c|}
\hline \multirow{3}{*}{$2 \theta\left(^{\circ}\right)$} & \multicolumn{15}{|c|}{ Intensity, a.u } \\
\hline & \multicolumn{5}{|c|}{ TPABr } & \multicolumn{5}{|c|}{ TPAOH } & \multicolumn{5}{|c|}{$\mathrm{TPABr}+\mathrm{TPAOH}$} \\
\hline & $\mathrm{Oh}$ & $6 \mathrm{~h}$ & $12 \mathrm{~h}$ & $18 \mathrm{~h}$ & $24 \mathrm{~h}$ & $\mathrm{Oh}$ & $6 \mathrm{~h}$ & $12 \mathrm{~h}$ & $18 \mathrm{~h}$ & $24 \mathrm{~h}$ & $\mathrm{Oh}$ & $6 \mathrm{~h}$ & $12 \mathrm{~h}$ & $18 \mathrm{~h}$ & $24 \mathrm{~h}$ \\
\hline $\begin{array}{c}22.95- \\
23.08\end{array}$ & $46.88^{*}$ & - & 502 & 484 & 497.77 & - & - & 269 & 450.92 & 512.83 & - & 166 & 437 & 524 & 520 \\
\hline $\begin{array}{c}23.11- \\
23.28\end{array}$ & - & - & 400 & 400 & 418.72 & - & - & 225 & 416.78 & 387.59 & - & 151 & 289 & 380 & 392 \\
\hline $\begin{array}{c}23.63- \\
23.69\end{array}$ & - & - & 262 & 207 & 204.06 & - & - & 154 & 239.27 & 227.85 & - & 114 & 262 & 253 & 237 \\
\hline $\begin{array}{c}23.85- \\
23.93\end{array}$ & - & 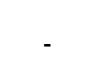 & 246 & 246 & 260.01 & - & - & 142 & 237 & 254.29 & - & 121 & 231 & 246 & 237 \\
\hline $24.33-24.8$ & $115.54^{\star}$ & $71.34^{*}$ & 174 & 161 & 148.76 & $91.35^{*}$ & $55.53^{*}$ & 119 & 146.56 & 189.63 & $94.73^{*}$ & $\begin{array}{c}25^{\star} \\
94\end{array}$ & 117 & 164 & 161 \\
\hline $\begin{array}{l}\text { ZSM-5 and } \\
\text { kaolin } \\
\text { Crystallinity } \\
(\%)^{\star *}\end{array}$ & $24.07^{*}$ & $14.79^{*}$ & 96.47 & 88.79 & 94.90 & $19.03^{*}$ & $11.45^{\star}$ & 56.41 & 92.50 & 97.57 & $19.70^{*}$ & $\begin{array}{l}5.20^{*} \\
40.09\end{array}$ & 82.90 & 97.25 & 96.01 \\
\hline
\end{tabular}

* $=$ kaolin

${ }^{* *}=$ The relative crystallinity calculated by formula, i.e (peak intensity of sample/ peak intensity of sample) $x 100 \%$ 


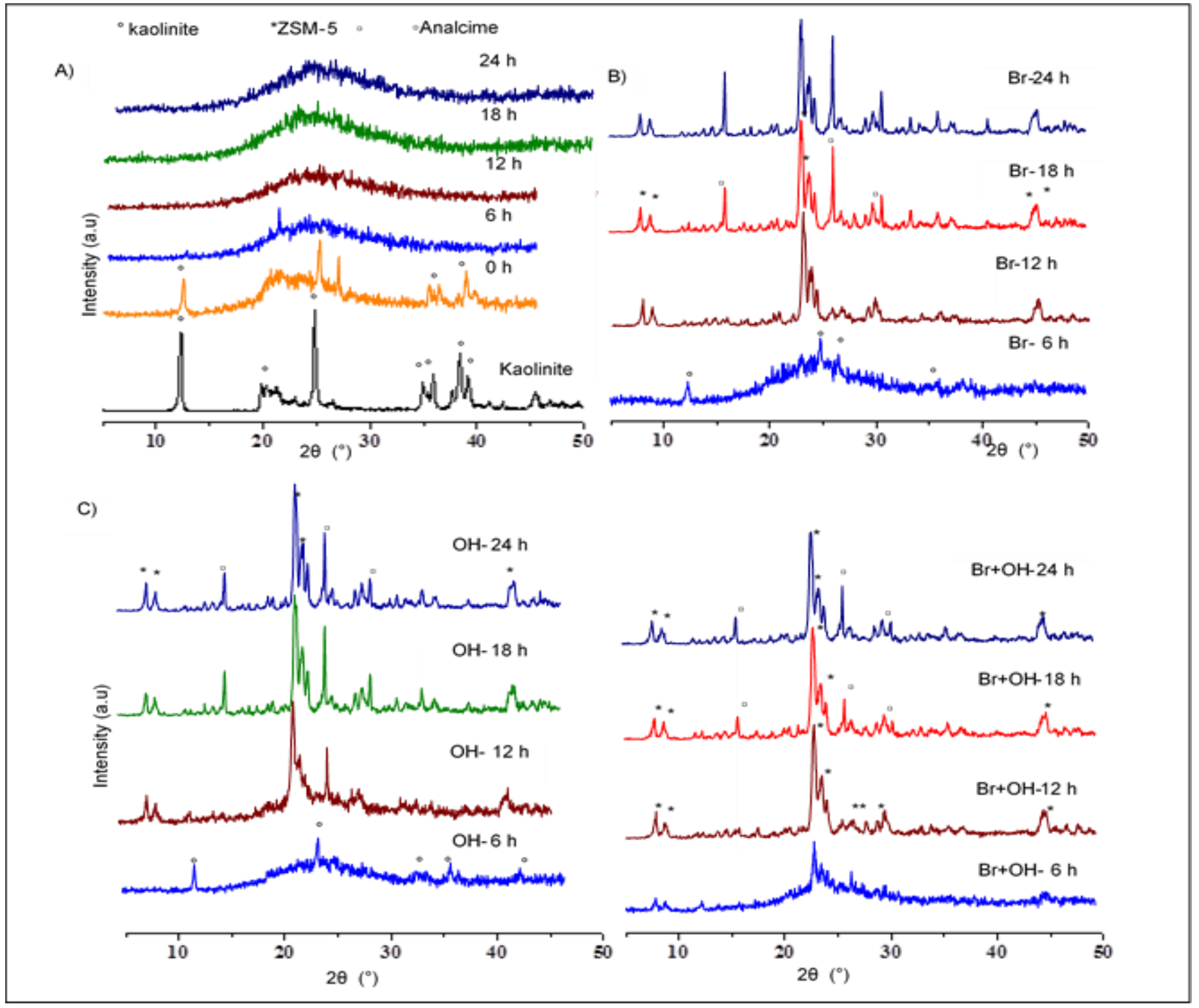

Fig. 1 XRD patterns of samples A) kaolin and without template, B) TPABr (Br), C) TPAOH (OH), and D) TPAOH + TPABr $(B r+O H)$ template
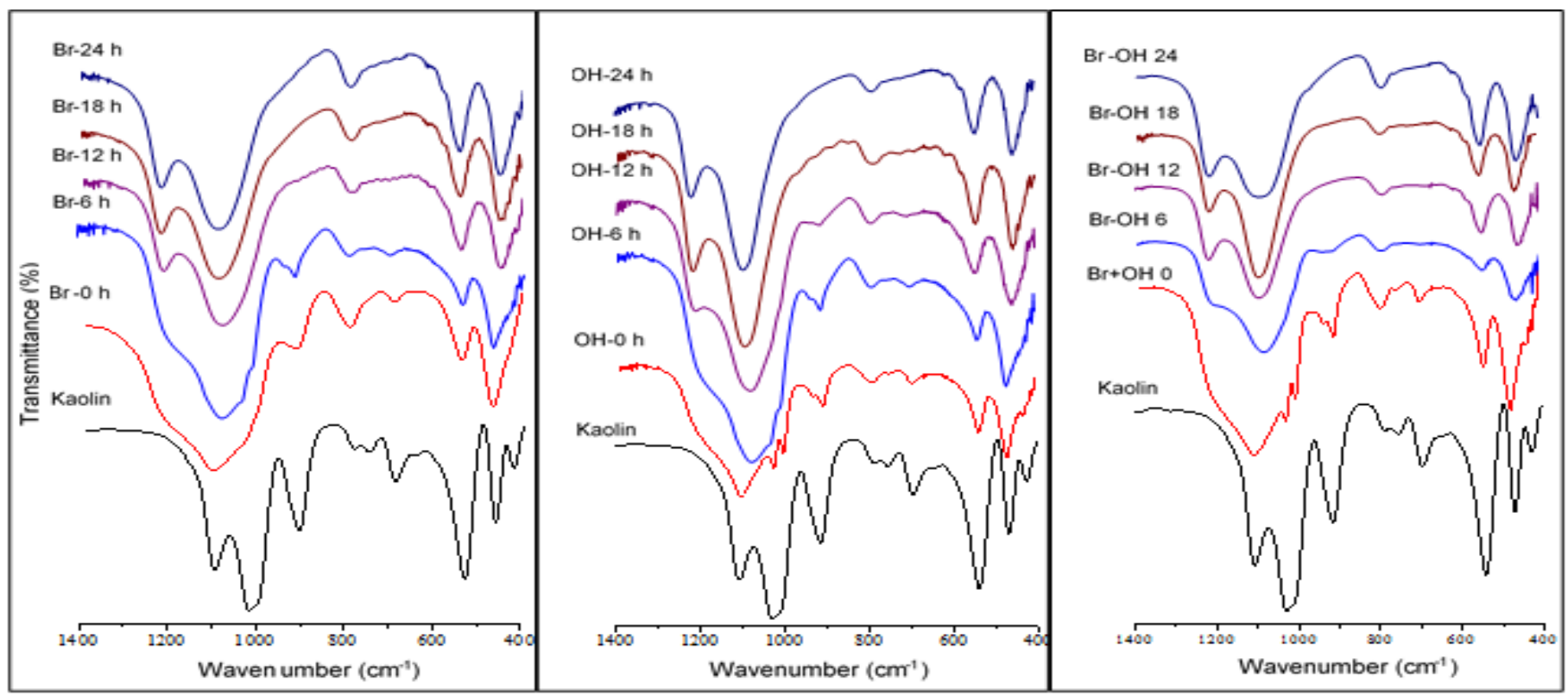

Fig. 2 Infrared spectra of the samples with variation of crystallization times at $0,6,12,18$ and $24 \mathrm{~h}$ with $\mathrm{TPABr}(\mathrm{Br}), \mathrm{TPAOH}(\mathrm{OH})$ and $\mathrm{TPABr}+\mathrm{TPAOH}(\mathrm{Br}+\mathrm{OH})$ as organic template, respectively. 
Table 2 Crystalline phases in different crystallization time and templates

\begin{tabular}{cccccc}
\hline \multirow{2}{*}{ No. } & Crystallization time $(\mathrm{h})$ & \multicolumn{3}{c}{ Phases } \\
\cline { 3 - 6 } & & TPABr & TPAOH & TPABr + TPAOH & Without template \\
\hline 1 & 0 & Kaolin & Kaolin & Kaolin & Kaolin \\
2 & 6 & Kaolin & Kaolin & Kaolin, ZSM-5 & Kaolin \\
3 & 12 & ZSM-5 & ZSM-5, analcime & ZSM-5 & Amorphous \\
4 & 18 & ZSM-5, Analcime & ZSM-5, Analcime & ZSM-5, Analcime & Amorphous \\
5 & 24 & ZSM-5, Analcime & ZSM-5, Analcime & ZSM-5, Analcime & Amorphous \\
\hline
\end{tabular}

Analysis on the dried samples for all reaction mixtures after $6 \mathrm{~h}$ of hydrothermal synthesis reveals the powder is still predominantly exists as kaolin without ZSM-5. All the characteristic peaks assigned to kaolin can be visibly observed, however the intensity reduces significantly suggesting the dissolution of crystalline kaolin to amorphous silica.

The presence of ZSM-5 in the synthesized product revealed by the infrared band at $545 \mathrm{~cm}^{-1}$, which corresponds to the five-member ring of the pentasil structure of zeolite (Kirschhock et al., 1999). In agreement with the XRD analysis, the ZSM-5 characteristic was observed at $12 \mathrm{~h}$ of reaction when TPABr was used and at $18 \mathrm{~h}$ for TPAOH and TPAOH + TPABr mixture. Structure-sensitive IR band for ZSM-5 at $\sim 1222 \mathrm{~cm}^{-1}$ corresponded to the external asymmetric stretching vibrations of Si-O-T bond was also appeared indicating the formation of ZSM-5 framework. In addition, the spectra of products display the strong bending vibration of the T-O bond appearing at about $446 \mathrm{~cm}^{-1}$. This is due to internal vibration of $(\mathrm{Si}, \mathrm{Al}) \mathrm{O}_{4}$ tetrahedral (Wang et al., 2012). Meanwhile, the shifting of the band at around $1100 \mathrm{~cm}^{-1}$ confirms the majority of Si-O-Si bonds in the silica gel (Hui et al., 2008). The presence of these bands are accompanied by the disappearance of the stretching vibration of $\mathrm{Si}-\mathrm{O}-\mathrm{H}$ groups of kaolin at $912 \mathrm{~cm}^{-1}$ indicating the incorporation of $\mathrm{Al}$ to the $\mathrm{Si}-\mathrm{OH}$ framework to form ZSM-5 structure.

The wavenumber at around $1090 \mathrm{~cm}^{-1}$ is assigned to the internal asymmetric stretching corresponds to the $\mathrm{Si} / \mathrm{Al}$ ratio in the zeolite samples. This band shifted to the higher wavenumber as the $\mathrm{Si} / \mathrm{Al}$ ratio increased (Sohn et al., 1986). It can be seen that the wavenumbers of internal asymmetric stretching have shifted from 1081 to $1089 \mathrm{~cm}^{-1}$ with the increase of crystallization times from 12 to $24 \mathrm{~h}$ with $\mathrm{TPABr}$ as organic template, whilst for samples with TPAOH, the wavenumber have shifted from 1080 to $1095 \mathrm{~cm}^{-1}$ for 6 to $24 \mathrm{~h}$ of crystallization time (Fig. 2). Meanwhile, the wavenumber has shifted from 1083 to $1095 \mathrm{~cm}^{-1}$ with the increase of crystallization time from 6 to $24 \mathrm{~h}$ with TPABr+TPAOH as organic template. This finding shows that the $\mathrm{Si} / \mathrm{Al}$ ratio increases as crystallization time increase. In other words, the amount of Si increases in the sample with the high asymmetric stretching wavenumber. This implies the rich silica ZSM-5 was obtained after $24 \mathrm{~h}$ of crystallization period for $\mathrm{TPABr}$, at $18 \mathrm{~h}$ for $\mathrm{TPAOH}$, and at $12 \mathrm{~h}$ for $\mathrm{TPABr}+\mathrm{TPAOH}$ templates.

\section{Dissolution and transformation of kaolin to ZSM-5}

We used the percentage of solid yield relative to the amount of kaolin used in the reaction to give an idea into the crystallization process. Fig. 3 indicates the correlation between the solid yield (wt\%) and the crystallization time of the synthesis. The amounts of initial solid products were around $12-6 \%$ indicating the dissolution of kaolin is not affected by the presence of organic template. XRD analysis of the solid samples showed that without organic template, the kaolin was transformed into amorphous silica within the first $6 \mathrm{~h}$ of the hydrothermal reaction.

In the presence of organic template, the reaction achieved optimum yield at around $12-18 \mathrm{~h}$ of reaction. Note that the amount of solid product obtained after $6 \mathrm{~h}$ of reaction is consists of amorphous silica and the transformation to ZSM-5 only occurred at $12 \mathrm{~h}$ or reactions apart from the reaction with a mixture of TPAOH and TPABr. Crystalline phases in different crystallization time and templates were summarized in Table 2. Since there is no decrease in the amount of solid product between 6-12 h of reaction, we can suggest that the transformation of kaolin to ZSM-5 proceed via amorphous silica intermediate which later re-arranged in the presence of organic template to from ZSM-5 framework. Extending the hydrothermal treatment up to $24 \mathrm{~h}$, do not significantly improve the amount of solid yield obtained.

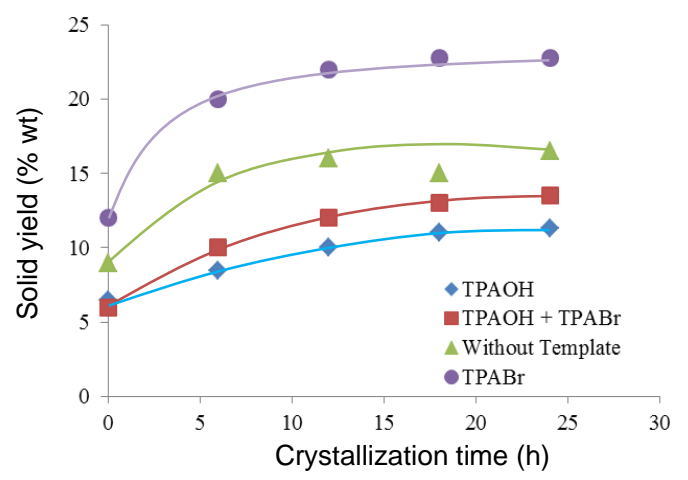

Fig. 3 The amount of solid product relative to different hydrothermal time

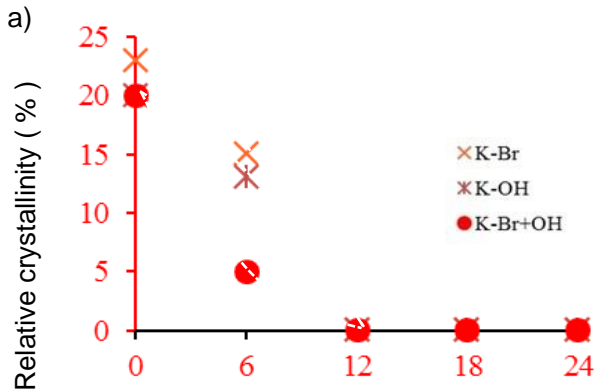

Crystallization times $(\mathrm{h})$

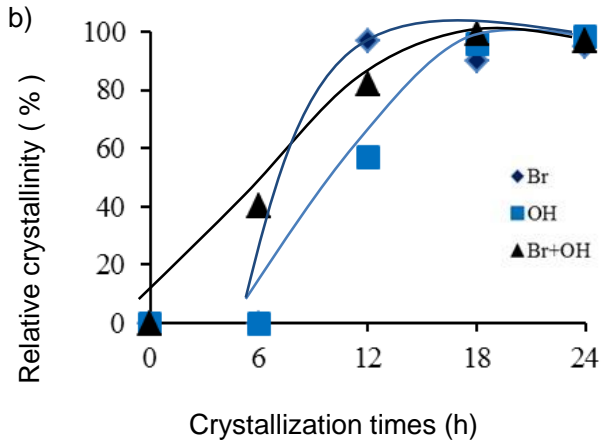

Fig. 4 Relative crystallinity of kaolin (a) and ZSM-5 (b) with different crystallization times

The XRD pattern of kaolin and ZSM-5 were used to understand the dissolution of kaolin and the formation of ZSM-5 under hydrothermal condition. Fig. 4 shows the relative crystallinity of kaolin and ZSM-5 calculated from the intensity of the diffraction peak of kaolin at $\sim 24.8^{\circ}$ (Fig. 4a for $\mathrm{K}-\mathrm{Br}, \mathrm{K}-\mathrm{OH}$, and $\mathrm{K}-\mathrm{Br}+\mathrm{OH}$ ) and ZSM-5 at $\sim 23.11^{\circ}$ (Fig. 4b with different form of TPA template for $\mathrm{Br}, \mathrm{OH}$, and $\mathrm{Br}+\mathrm{OH})$. The dissolution of kaolin into amorphous silica is important step for ZSM-5 formation. The use of TPAOH and $\mathrm{TPABr}$ as a structure-directing agent is a common method for synthesizing ZSM-5, however the presence of $\mathrm{OH}$ - anion on TPAOH influence the $\mathrm{pH}$ of the reaction mixture. The $\mathrm{pH}$ of the reaction 
mixture using TPAOH was 12 which are relatively higher than the mixture of TPABr and $\mathrm{TPAOH}, 11.6$ and $\mathrm{TPABr}, 11$. The presence of extra $\mathrm{OH}$ - anion in TPAOH changes the $\mathrm{OH} / \mathrm{Al}_{2} \mathrm{O}_{3}$ ratios of the mixture from 10 to 5 . The significant of the difference in the $\mathrm{OH}$ concentration of the solution can be seen by the amount of solid powder remain at the initial time of the reaction.

We observed the rate of kaolin dissolution differ for each reactions with the rate is in the order of TPAOH+TPABr $>\mathrm{TPAOH}>$ TPABr. The $\mathrm{OH}^{-}$anion dissolves kaolin into siliceous gel and subsequently transform into a liquid presumably in the form of $\mathrm{H}_{2} \mathrm{SiO}_{3}$ or $\mathrm{H}_{4} \mathrm{SiO}_{4}$ (Pan et al., 2014). The hydrated sodium ion favors the formation of 5-1 secondary building units that formed by tetrahedral $\left(\mathrm{AlO}_{4}\right)^{-5}$ and $\left(\mathrm{SiO}_{4}\right)^{-4}$ units linked through shared oxygen atoms, which is necessary for nucleation and crystallization of ZSM-5 (Pan et al., 2014). The dissolution of kaolin into amorphous silica is importance to initiate ZSM-formation. When $\mathrm{TPABr}$ and $\mathrm{TPAOH}$ mixture were used as organic template, a high rate of kaolin dissolution were observed which subsequently initiates ZSM-5 nucleation at $6 \mathrm{~h}$ of reaction. In contrast the reaction using TPAOH and TPABr respectively only produce ZSM-5 at $12 \mathrm{~h}$ of reaction.

\section{SEM EDX}

Scanning electron microscopy (Fig. 5) and EDX analysis (Table 3 ) were employed to investigate the morphology and chemical composition of kaolin and synthesized ZSM-5. The kaolin and ZSM-5 have different crystal morphology as kaolin appeared as random plate shaped structure (Fig. 5a). ZSM-5 synthesis using TPABr organic template after $12 \mathrm{~h}$ of crystallization shows aggregated with spherical shape and rough surface as shown in Fig $5 \mathrm{~b}$. The ratio of $\mathrm{Si} / \mathrm{Al}$ calculated from the EDX data is $\sim 7.29$ and the size of crystal is $\sim 1-2$ $\mu \mathrm{m}$. Extending the crystallization period up to $24 \mathrm{~h}$ shows large spherical crystallite which reveal the agglomerated of ZSM-5 and analcime with the size of $\sim 2-3 \mu \mathrm{m}$ (Fig. $5 \mathrm{c}$-e). The EDX analysis of this crystallite (Fig. $5 \mathrm{~d}$ ) reveals the ratio of $\mathrm{Si} / \mathrm{Al}$ is $\sim 2.5$, which is corresponded to the chemical composition of analcime crystalline phase as reported by Park et al., (2012). This is in agreement with the XRD analysis that shows the transformation of ZSM-5 to analcime at $24 \mathrm{~h}$.

Fig. $5 \mathrm{f}$ shows the SEM image of ZSM-5 using TPAOH after $12 \mathrm{~h}$ of hydrothermal synthesis. The spherical aggregated crystallite forms with the size in the range of $0.5-1.0 \mu \mathrm{m}$. The Si/Al ratio of the sample calculated on the basis of EDX data showed that $\mathrm{Si} / \mathrm{Al}$ ratio is $\sim 5.69$. Fig 5g-h showed the morphology of ZSM-5 using a mixture of $\mathrm{TPABr}$ and TPAOH organic template after $12 \mathrm{~h}$ of crystallization. The crystallites are consisted of spherical aggregates with the size around $1 \mu \mathrm{m}$. The $\mathrm{Si} / \mathrm{Al}$ ratio of these shaped were 5.84 corresponded to the ZSM-5 (Fig. 5g). The synthesized ZSM-5 morphology also consists of a large hexagonal shaped crystallite $\sim 10 \mu \mathrm{m}$ with the $\mathrm{Si} / \mathrm{Al}$ ratio of 2.41 (Fig. 5h). This relatively large crystallite size and low $\mathrm{Si} / \mathrm{Al}$ ratio are indicative of analcime crystal structure (English, 2011).
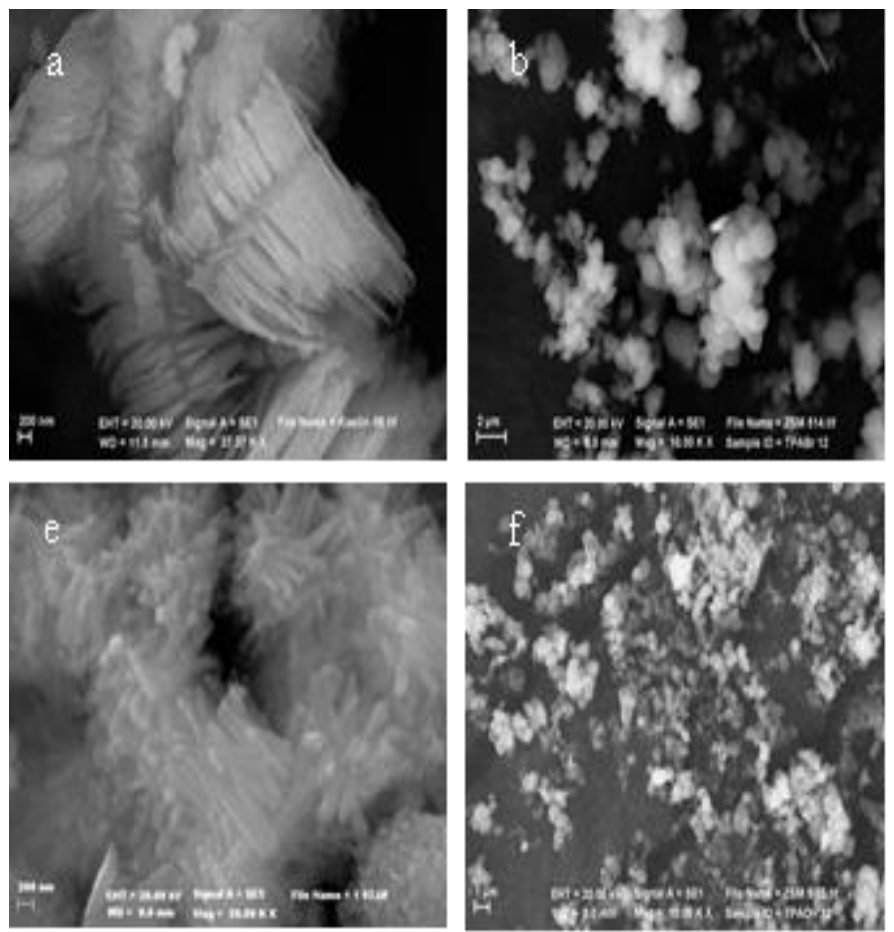
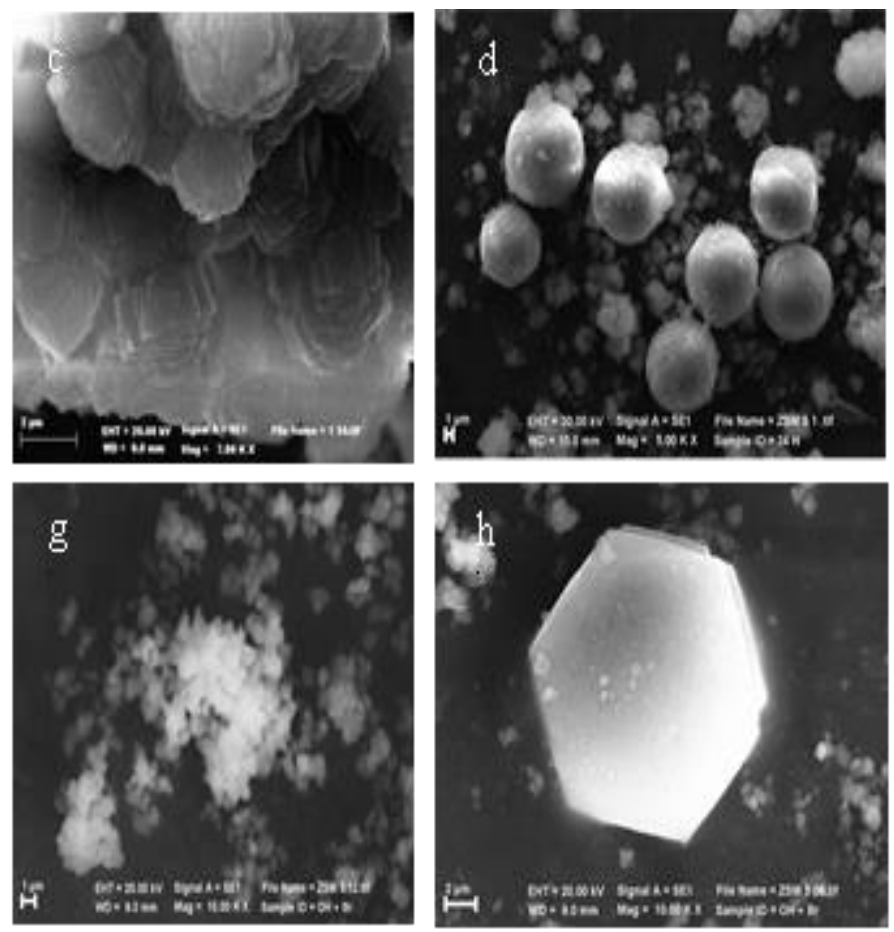

Fig. 5 SEM image of (a) kaolin; and ZSM-5 using TPABr at (b) 12 h; (c-e) 24 h; (f) using TPAOH at 12 h; (g-h) using TPAOH and TPABr at 12 h

Table 3 EDX analysis was employed to investigate the chemical composition of kaolin and synthesized ZSM-5

\begin{tabular}{lcccccc}
\hline \multirow{2}{*}{ Sample } & \multicolumn{7}{c}{ Chemical composition (wt\%) } \\
\cline { 2 - 7 } & $\mathrm{Si}$ & $\mathrm{Al}$ & $\mathrm{Na}$ & $\mathrm{O}$ & $\mathrm{K}$ & $\mathrm{Si}^{\circ} \mathrm{Al}^{*}$ \\
\hline Kaolin & 12.59 & 15.88 & - & 71.24 & 0.29 & 0.79 \\
Br-12h & 26.33 & 3.61 & 3.27 & 66.78 & - & 7.29 \\
$\mathrm{Br-24h}$ & 14.48 & 6.59 & 8.20 & 68.48 & - & 2.50 \\
OH-12h & 12.80 & 2.25 & 2.44 & 82.50 & - & 5.69 \\
$\mathrm{Br+OH}$ 12h (ZSM-5) & 5.31 & 0.91 & 1.63 & 92.15 & - & 5.84 \\
$\mathrm{Br+OH12h}$ (Analcime) & 6.41 & 2.66 & 3.44 & 87.48 & - & 2.41 \\
$\mathrm{Br+OH}$ 24h & 16.48 & 10.32 & 8.20 & 68.73 & - & 2.50 \\
\hline
\end{tabular}

*The molar ratio of Si/Al in sample 


\section{CONCLUSION}

Parameters such as silica precursor, structure-directing agent, basicity of the reaction mixture and crystallization period are crucially important for zeolite synthesis. We found that kaolin can be used as alternative silica and alumina precursor for ZSM-5 synthesis without prior pre-treatment. The transformation of kaolin to ZSM-5 proceeded via dissolution of kaolin to amorphous silica. The use of organic template is important to initiate ZSM-5 framework formation and we observed a synergistic influence of $\mathrm{TPAOH}$ and $\mathrm{TPABr}$ mixture to accelerate the nucleation of ZSM-5.

\section{ACKNOWLEDGEMENT}

Financial support from the Ministry of Research and Higher Education (under "PUPT" research grant No. 003246.18/IT2.11/PN.08/2015) is gratefully acknowledged.

\section{REFERENCES}

[1] D. J. Kim, H. S. Chung, Appl. Clay Sci. 24 (2003) 69-77.

[2] P. Wang, B. Shen, D. Shen, T. Peng, J. Gao. Catal. Commun. 8 (2007) 1452-1456.

[3] D. Prasetyoko, N. Ayunanda, H. Fansuri, D. Hartanto, Z. Ramli, J. Math. Fund. Sci. 44 (2012) 250-262.

[4] H. Tanaka and A. Fujii, Powder Technol. 20 (2009) 473-479.
[5] H. Feng, C. Li, H. Shan, Appl. Clay Sci. 42 (2009) 439-445.

[6] F. Pan, X. Lu, Y. Wang, S. Chen, T. Wang, Y. Yan, Microporous Mesoporous Mater. 184 (2014) 134-140.

[7] M. Alkan, C. Hopa, Z. Yilmaz, H. Guler, Microporous Mesoporous Mater. 86 (2005) 176-184.

[8] E. B. G. Johnson and S.E. Arshad, Appl. Clay Sci. 97-98 (2014) 215221.

[9] V. P. Shiralkar and A. Clearfield, Zeolites 9 (1989) 363-370.

[10] K. Byrappa and M. Yoshimura, Handbook of Hydrothermal Technology, USA: Noyes Publications, (2013).

[11] R. Karimi, B. Bayati, N. C. Aghdam, M. Ejtemaee, A. A. Babaluo, Powder Technol. 229 (2012) 229-236.

[12] I. Qoniah, D. Prasetyoko, H. Bahruji, S. Triwahyono, A. A. Jalil, Suprapto, Hartati, T. E. Purbaningtias, Appl. Clay Sci. 118 (2015) 290294.

[13] M. M. J. Treacy, J. B. Higgins, R. Von Balloms, Collection of simulated $X R D$ powder patterns for zeolite (4th edition), Amsterdam: Elsevier (2001).

[14] S. H. Park, C. H. Chung, G. Seo, Microporous Mesoporous Mater. 155 (2012) 201-207.

[15] C. A. Rios, C. D. Williams, M. A. Fullen, Appl. Clay Sci. 42 (2009) 446454.

[16] C. E. A. Kirschhock, R. Ravishankar, F. Verspeurt, P. J. Grobet, P. A. Jacobs, J. A. Martens, J. Phys. Chem. 103 (1999) 4965-4971.

[17] J. Wang, X. L. Wu, J. X. Wang, C. Z. Liu, Y. M. Lai, Z. K. Hong, Microporous Mesoporous Mater. 155 (2012) 186-191.

[18] F. Hui, C. Yan-hong, L. Chun-yi, S. Hong-hong, J. Fuel Chem. Technol. 36 (2008) 144-150.

[19] J. R. Sohn, S. J. DeCanio, J. H. Lunsford, Zeolites 6 (1986) 225-227.

[20] P. M. English, Sedimentary Geology $143 \quad$ (2011) 219-244. 